\title{
Toward an understanding of sexual harassment in neurosurgery
}

\author{
Deborah L. Benzil, MD, ${ }^{1}$ Karin M. Muraszko, MD, ${ }^{2}$ Pranay Soni, MD, ${ }^{1}$ Ellen L. Air, MD, PhD, ${ }^{3}$ \\ Katie O. Orrico, JD, ${ }^{4}$ and James T. Rutka, MD, PhD ${ }^{5}$
}

\begin{abstract}
1Department of Neurosurgery, Cleveland Clinic, Cleveland, Ohio; 2Department of Neurosurgery, University of Michigan, Ann Arbor, Michigan; ${ }^{3}$ Department of Neurosurgery, Henry Ford Health System, Detroit, Michigan; ${ }^{4}$ Washington Office, American Association of Neurological Surgeons/Congress of Neurological Surgeons, Washington, DC; and 5epartment of Neurosurgery, The Hospital for Sick Children, University of Toronto, Ontario, Canada
\end{abstract}

OBJECTIVE The goal of this study was the creation and administration of a survey to assess the depth and breadth of sexual harassment across neurosurgery.

METHODS A survey was created to 1) assess perceived attitudes toward systemic issues that might be permissive of sexual harassment; 2) measure the reported prevalence and severity of sexual harassment; and 3) determine the populations at highest risk and those most likely to perpetrate sexual harassment. Demographic information was also included to facilitate further analysis. The SurveyMonkey platform was used, and a request to complete the survey was sent to all Society of Neurological Surgeons and Congress of Neurological Surgeons (CNS) active and resident members as well as CNS transitional, emeritus, and inactive members. Data were analyzed using RStudio version 1.2.5019.

RESULTS Nearly two-thirds of responders indicated having witnessed sexual harassment in some form $(62 \%, n=382)$. Males were overwhelmingly identified as the offenders in allegations of sexual harassment $(72 \%)$, with individuals in a "superior position" identified as offenders in $86 \%$. Less than one-third of responders addressed the incidents of sexual harassment when they happened (yes 31\%, no 62\%, unsure 7\%). Of those who did report, most felt there was either no impact or a negative one (negative: $34 \%$, no impact: $38 \%$ ). Almost all (85\%) cited barriers to taking action about sexual harassment, including retaliation/retribution (87\%), impact on future career (85\%), reputation concerns (72\%), and associated stress (50\%). Female neurosurgeons were statistically more likely than male neurosurgeons to report witnessing or experiencing sexual harassment, as well as assessing it as a problem.

CONCLUSIONS This study demonstrates that neurosurgeons report significant sexual harassment across all ages and practice settings. Sexual harassment impacts both men and women, with more than half personally subjected to this behavior and two-thirds having witnessed it. Male dominance, a hierarchical environment, and a permissive environment remain prevalent within the neurosurgical community. This is not just a historical problem, but it continues today. A change of culture will be required for neurosurgery to shed this mantle, which must include zero tolerance of this behavior, new policies, awareness of unconscious bias, and commitment to best practices to enhance diversity. Above all, it will require that all neurosurgeons and neurosurgical leaders develop an awareness of sexual harassment in the workplace and establish consistent mechanisms to mitigate against its highly deleterious effects in the specialty.

https://thejns.org/doi/abs/10.3171/2020.6.JNS201649

KEYWORDS sexual harassment; neurosurgery; diversity; burnout; engagement

$\mathrm{S}$ EXUAL harassment has serious and significant consequences for the individual, institutions, and all of medicine. ${ }^{1-3}$ A clear definition of sexual harassment includes gender harassment, unwanted sexual attention, and sexual coercion. ${ }^{4}$ Studies have shown a high prevalence of sexual harassment during medical school and residency, as well as among faculty., ${ }^{2,5,6}$ Many stud- ies demonstrate a negative impact of sexual harassment on engagement and career satisfaction, along with causing or accentuating burnout. These behaviors also affect trainees' choice of specialty - an important effect to understand in any efforts to attract women to traditionally male-dominated medical fields. ${ }^{7,8}$

A landmark report by the National Academies of Sci-

ABBREVIATIONS AANS = American Association of Neurological Surgeons; $C N S=$ Congress of Neurological Surgeons; NSPT = Neurosurgery Professionalism Taskforce; SNS = Society of Neurological Surgeons.

ACCOMPANYING EDITORIAL See pp 339-341. DOI: 10.3171/2020.8.JNS202583.

SUBMITTED May 14, 2020. ACCEPTED June 30, 2020.

INCLUDE WHEN CITING Published online November 10, 2020; DOI: 10.3171/2020.6.JNS201649. 
ences, Engineering, and Medicine (NASEM) delineated the finding that the risk of sexual harassment increases with historical male dominance, strong hierarchies, and a culture that fails to acknowledge mistreatment. ${ }^{4}$ Studies have identified surgery (and surgical specialties) as high risk, with surgical consultants/faculty as the most frequent offenders. ${ }^{9}$ Given these characteristics, neurosurgery as a subspecialty would appear to be at high risk; however, a comprehensive and systematic evaluation of sexual harassment and bias in neurosurgery has not previously been conducted. Although recent news reports have brought the topic of sexual harassment into the spotlight, concern within the medical community has existed for years. ${ }^{1,710,11}$ There remains an urgent need to use valid measures to define a complete profile of the problem within medicine, especially in specialties such as neurosurgery that are likely to be at high risk. ${ }^{12}$

Perceptively, in 2018 the One Neurosurgery Summit (American Association of Neurological Surgeons [AANS], Congress of Neurological Surgeons [CNS], American Board of Neurological Surgery [ABNS], Society of Neurological Surgeons [SNS], American Academy of Neurological Surgery [AAcNS], Residency Review Committee for Neurological Surgery [RRC], and AANS/ CNS Washington Committee) convened the Neurosurgery Professionalism Taskforce (NSPT) (members: Ellen L. Air, MD, PhD; James R. Bean, MD; Deborah L. Benzil, MD; Linda M. Liau, MD; Catherine A. Mazzola, MD; Karin M. Muraszko, MD; Katie O. Orrico, JD; James T. Rutka, MD, PhD; and Alan Scarrow, MD). Under the leadership of Drs. Rutka and Muraszko, the goal of the NSPT was to provide a comprehensive report on policy and recommendations regarding sexual harassment in neurosurgery. Although the NSPT undertook many activities, one major initiative was the creation and administration of a survey to assess the depth and breadth of sexual harassment across neurosurgery. This report outlines the key findings of that significant survey.

\section{Methods \\ Survey Design}

A review of the literature did not reveal a single standard survey mechanism for a comprehensive assessment of current and past sexual harassment, and there is considerable controversy about some of the existing tools..$^{13,14}$ Available templates ranged from a long and detailed survey from the US military ${ }^{15}$ to university or medical organization surveys. ${ }^{16}$ Any previously validated questions were incorporated when appropriate. The agreed-upon goals of the survey were to 1) assess perceived attitudes toward systemic issues that might be permissive of sexual harassment; 2) measure the reported prevalence and severity of sexual harassment; and 3) determine the populations at highest risk and those most likely to perpetrate sexual harassment. The collection of necessary demographic information was also included to facilitate further analysis. Best practices with survey design were used, and pilot testing was completed before the final survey was administered.

The first 20 questions primarily addressed systemic is- sues through a series of inquiries answered on a Likert scale (from "agree strongly" to "disagree strongly"). Several questions assessed sexual harassment policies. The remaining questions directly addressed sexual harassment occurrence, reporting, environment, and responsible individuals-requiring specific answers but with options for comments. The final question before the collection of demographic information allowed respondents the opportunity to relate details about "the worst experience with sexual harassment" endured during a neurosurgical meeting/program. Demographic questions used standard skip logic for appropriate stratification (see Supplemental Appendix 1 for the complete survey).

\section{Survey Population and Dissemination}

The One Neurosurgery Summit agreed to disseminate the questionnaire under the aegis of the SNS, and it was administered by the CNS. The SurveyMonkey platform was used, and a request to complete the survey was sent to all SNS and CNS active and resident members, as well as to CNS transitional, emeritus, and inactive members. Three email messages were distributed to a total of 5166 individuals, with 5155 initial email invitations to participate sent out beginning January 13, 2020; follow-up email reminders were then sent on January 27, 2020, and February 10, 2020. The survey was closed on February 23,2020 . A total of 622 respondents (12\%) completed the entire survey; in all, 643 surveys (some partially completed) were returned. All usable data were included in the analysis.

\section{Statistical Analysis}

Data were analyzed using RStudio version 1.2.5019 (https://rstudio.com/products/team/). Descriptive statistics were reported using both $\mathrm{N}$ values and percentages of the total, and chi-square tests were performed to identify differences between gender and age group cohorts. Statistical significance was defined as $\mathrm{p}<0.05$.

\section{Results}

\section{Survey Response and Demographics}

The response rate was $12 \%$, of which $20 \%$ of respondents were women. This is slightly higher than the total percentage of women in neurosurgery (currently 19\% of all residents and $8 \%$ of all practicing neurosurgeons; personal communication, AANS office) and in the database used for emailing. Age distribution and other demographic factors also deviated slightly from a practice database in terms of age and practice type (Table 1). There was a relatively high rate of respondents who indicated cerebrovascular (20\% of respondents vs $13 \%$ in neurosurgery as a whole) and pediatrics (16\% vs $10 \%$ in neurosurgery as a whole) as a subspecialty and a lower rate of those specifying spine/peripheral nerve (16\% vs $41 \%$ in neurosurgery as a whole).

\section{Incidence and Extent of Sexual Harassment}

Nearly two-thirds of responders witnessed sexual harassment in some form $(62 \%, \mathrm{n}=382)$ (Table 2$)$. A slightly 
TABLE 1. Survey respondent demographics and practice characteristics

\begin{tabular}{|c|c|c|c|}
\hline Demographic & Respondents & Demographic & Respondents \\
\hline Gender $(n=584)$ & & Practice size $(n=524)$ & \\
\hline Female & 121 & Large/multispecialty & 122 \\
\hline Male & 457 & Large/single specialty & 42 \\
\hline Other & 6 & Medium/multispecialty & 74 \\
\hline Age $(n=584)$ & & Medium/single specialty & 160 \\
\hline$<40$ yrs & 170 & Small/multispecialty & 10 \\
\hline $41-50$ yrs & 139 & Small/single specialty & 81 \\
\hline $51-60$ yrs & 129 & Solo practice & 21 \\
\hline$>60 \mathrm{yrs}$ & 146 & Solo with shared facilities & 6 \\
\hline Region $(n=523)$ & & Multiple & 1 \\
\hline Northeast & 116 & Other & 7 \\
\hline Midwest & 134 & Practice setting $(n=524)$ & \\
\hline South & 163 & Academic & 342 \\
\hline West & 90 & Armed forces & 2 \\
\hline US territory & 3 & Government & 11 \\
\hline Canada & 12 & Community & 169 \\
\hline Mexico & 1 & Subspecialty $(n=517)$ & \\
\hline Multiple & 2 & Cerebrovascular & 104 \\
\hline Practice location $(n=524)$ & & Endoscopy & 1 \\
\hline Rural & 33 & Functional & 31 \\
\hline Suburban & 133 & General & 109 \\
\hline Urban & 358 & Neurocritical care/trauma & 13 \\
\hline Employment $(n=524)$ & & Pain & 4 \\
\hline Academic & 310 & Pediatrics & 81 \\
\hline Government & 6 & Resident & 17 \\
\hline Hospital-employed & 88 & Skull base & 1 \\
\hline Private with academic & 62 & Spine/peripheral nerve & 91 \\
\hline Private practice & 56 & Tumor & 64 \\
\hline Multiple & 1 & Multiple & 1 \\
\hline Other & 1 & & \\
\hline
\end{tabular}

Discrepancies in totals throughout the tables reflect the fact that not all respondents answered all questions, and some questions had multiple options.

smaller cohort reported having been personally subjected to some form of sexual harassment $(55 \%, \mathrm{n}=334)$. Of these, $78 \%$ were subjected to this behavior during training $(\mathrm{n}=262)$, nearly half during postresidency employment $(49 \%, \mathrm{n}=163)$, and a significant cohort at a national meeting or other educational offering $(17 \%, \mathrm{n}=55$ for each). Perhaps most distressing was that more than one-third $(37 \%, \mathrm{n}=122)$ had experienced this behavior more than 10 times and another 19\% $(n=62)$ more than 5 times. In addition, the survey clearly demonstrates these are not just historical transgressions - there was a fairly even distribution between less than 1 year and more than 10 years ago. The most commonly reported behavior was the telling of explicit or offensive jokes (49\%). There was also a significant incidence of unwelcome flirtations (22\%), inappropriate physical contact (16\%), discussion about sex/personal life (18\%), and inappropriate comments about the body $(15 \%)$. Although rare, rape was reported by 2 individuals $(<1 \%)$.

\section{Neurosurgical Environmental Factors Related to Sexual Harassment}

Given societal patterns and the high proportion of male neurosurgeons, it is not surprising that men were overwhelmingly identified as the offenders in allegations of sexual harassment (72\%), although $23 \%$ reported harassment by persons of both genders. Hierarchical structure was also identified as a significant contributing cause, with individuals in a "superior position" (chair, faculty, supervisor, etc.) being reported as responsible in an overwhelming proportion of cases (86\%). Those in lateral positions (colleagues, fellow residents) were frequently responsible as well (43\%).

Numerous environmental factors were evaluated to identify risk factors for the incidence of sexual harassment (Table 3). In a series of questions asking "With respect to discrimination, bullying/intimidation and/or sexual harassment, please rate the following statements regarding neurosurgery," most responses were neutral ("neither agree nor 
TABLE 2. Gender and age breakdown of respondents who witnessed behaviors in other individuals

\begin{tabular}{|c|c|c|c|c|c|}
\hline Survey Question & All Respondents & \multicolumn{2}{|c|}{ Female } & Male & p Value \\
\hline \multicolumn{6}{|c|}{$\begin{array}{l}\text { Have you witnessed discrimination, bullying/intimidation and/ } \\
\text { or sexual harassment toward individuals other than yourself? }\end{array}$} \\
\hline Yes & $382(62 \%)$ & \multicolumn{2}{|c|}{$103(85 \%)$} & $256(56 \%)$ & \\
\hline No & $193(31 \%)$ & \multicolumn{2}{|c|}{$10(8 \%)$} & $172(38 \%)$ & $<0.001$ \\
\hline \multirow[t]{3}{*}{ Unsure } & $41(7 \%)$ & \multicolumn{2}{|c|}{$8(7 \%)$} & $29(6 \%)$ & \\
\hline & \multicolumn{4}{|c|}{ Age of Respondents } & \\
\hline & $<40$ Yrs & $41-50$ Yrs & $51-60$ Yrs & $>60$ Yrs & \\
\hline \multicolumn{6}{|l|}{ Same question as above } \\
\hline Yes & $114(67 \%)$ & $87(63 \%)$ & $78(60 \%)$ & $82(56 \%)$ & \multirow{3}{*}{0.618} \\
\hline No & $47(28 \%)$ & $42(30 \%)$ & $43(33 \%)$ & $54(37 \%)$ & \\
\hline Unsure & $9(5 \%)$ & $10(7 \%)$ & $8(6 \%)$ & $10(7 \%)$ & \\
\hline
\end{tabular}

Boldface type indicates statistical significance.

disagree") or "agree." However, neurosurgery overall provided a less supportive and inclusive culture than individual settings (training environment, national meetings, educational programs, evaluation/testing, and preresidency).

Most felt that "people I have worked with [were] respectful and civil" (agree/strongly agree) for neurosurgery colleagues $(84 \%)$, faculty/leadership during training $(67 \%)$, and industry personnel $(85 \%)$. Most did not agree with "feeling excluded from opportunities," but to varying degrees (disagree/disagree strongly with feeling excluded by neurosurgery colleagues, 54\%; faculty/leadership during training, 64\%; and industry personnel, 67\%). A very similar pattern was reported in response to "exclusion from informal networking."

When asked to "rate your confidence in addressing unprofessional behavior... without reprisal from the following individuals," about half stated very high/high for neurosurgery colleagues (48\%), faculty/leadership during training (42\%), and industry personnel (54\%). Questions about national meetings and educational settings each led to a similar rate of confidence in the ability to address unprofessional behavior (very high/high for $45 \%$ and $51 \%$, respectively). Only $6 \%$ identified sexual harassment as very or extremely problematic at national meetings, courses, and workshops, but only $48 \%$ felt it was no problem at all ("somewhat," 19\%; "a little," 29\%).

\section{Minimal Reporting of Sexual Harassment}

Less than one-third addressed the incidents of sexual harassment when they happened (yes 31\%, no 62\%, unsure $7 \%$ ). The mechanism of addressing the event varied, with less than half reporting it in any official capacity, most just discussing it with another person. Almost all $(85 \%)$ cited barriers to taking action about sexual harassment, including retaliation/retribution (87\%), impact on future career $(85 \%)$, reputation concerns $(72 \%)$, and associated stress $(50 \%)$. Ramifications of reporting were feared from colleagues $(89 \%)$, hospitals $(57 \%)$, and organized neurosurgery (52\%). Program leadership, faculty, institutional leadership, referring doctors, and employed medical group were identified as potential sources of ramifications under the "other" category. Unfortunately, for those who did report, most felt there was either no impact or a negative one (negative: $34 \%$, no impact: $38 \%$ ).

\section{Identified Gender Differences}

Not surprisingly, female neurosurgeons were statistically more likely than male neurosurgeons to report witnessing or experiencing sexual harassment and to assess it as a problem (Tables 3 and 4). They also reported more concern about the neurosurgical environment in terms of support, respect, civility, inclusiveness, and safety. Women had less confidence in safety from reprisal if reporting sexual harassment as well $(p=0.006)$. However, in questions related to the existence or need for policy, a gender difference was not found. In fact, both men and women overwhelmingly ( $83 \%$ and $75 \%$, respectively) supported the need for policies by national neurosurgical organizations to mitigate against sexual harassment.

\section{Identified Age-Related Differences}

Age-related differences were less pronounced than gender differences. Older cohorts reported experiencing sexual harassment less during training, though more in postresidency employment $(\mathrm{p}<0.001)$ (Table 5). Younger cohorts noted a higher number of occurrences, with those 50 years or younger most frequently reporting more than 10 events $(>40 \%, \mathrm{p}=0.007)$. Younger neurosurgeons were more likely to discuss these behaviors with family/friends, peers, or mentors/senior colleagues. Whereas a large percentage felt there were barriers to reporting this behavior, those younger than 40 and between 41 and 50 years of age were statistically more likely to express concern about retaliation/retribution (95\% and $91 \%$, respectively; $\mathrm{p}=0.006$ ) and were more likely to cite negative ramifications from organized neurosurgery $(\mathrm{p}=$ $0.007)$ and the hospital $(\mathrm{p}=0.004)$. Of the behaviors experienced, the most notable difference was "inappropriate comments about body" ( $p<0.001)$. Younger groups agreed less that neurosurgery and neurosurgery meetings provided an inclusive and supportive culture that deals 
TABLE 3. Overall and gender-specific responses to questions regarding the culture in neurosurgery and its settings of interaction

\begin{tabular}{|c|c|c|c|c|}
\hline \multirow[b]{2}{*}{ Survey Question } & \multicolumn{3}{|c|}{ No. of Responses (\%) } & \multirow[b]{2}{*}{$\mathrm{p}$ Value } \\
\hline & All Respondents & Female & Male & \\
\hline \multicolumn{5}{|c|}{$\begin{array}{l}\text { Neurosurgery provides a supportive and inclusive culture that deals effectively with } \\
\text { these behaviors. }\end{array}$} \\
\hline Strongly disagree & $64(10 \%)$ & $30(25 \%)$ & $33(7 \%)$ & \multirow{5}{*}{$<0.001$} \\
\hline Disagree & $119(19 \%)$ & $40(33 \%)$ & $67(15 \%)$ & \\
\hline Neither agree nor disagree & $163(25 \%)$ & $31(26 \%)$ & $120(26 \%)$ & \\
\hline Agree & $174(27 \%)$ & $15(12 \%)$ & $131(29 \%)$ & \\
\hline Strongly agree & $123(19 \%)$ & $5(4 \%)$ & $106(23 \%)$ & \\
\hline \multicolumn{5}{|c|}{$\begin{array}{l}\text { My training environment (including the leadership) provides/provided a supportive } \\
\text { and inclusive culture that deals effectively with these behaviors. }\end{array}$} \\
\hline Strongly disagree & $64(10 \%)$ & $27(22 \%)$ & $34(7 \%)$ & \multirow{5}{*}{$<0.001$} \\
\hline Disagree & $107(17 \%)$ & $29(24 \%)$ & $65(14 \%)$ & \\
\hline Neither agree nor disagree & $87(14 \%)$ & $22(18 \%)$ & $58(13 \%)$ & \\
\hline Agree & $194(30 \%)$ & $29(24 \%)$ & $141(31 \%)$ & \\
\hline Strongly agree & $191(30 \%)$ & $14(12 \%)$ & $159(35 \%)$ & \\
\hline \multicolumn{5}{|c|}{$\begin{array}{l}\text { Neurosurgical meetings provide a supportive and inclusive culture that deals ef- } \\
\text { fectively with these behaviors. }\end{array}$} \\
\hline Strongly disagree & $33(5 \%)$ & $13(11 \%)$ & $18(4 \%)$ & \multirow{5}{*}{$<0.001$} \\
\hline Disagree & $73(11 \%)$ & $33(27 \%)$ & $37(8 \%)$ & \\
\hline Neither agree nor disagree & $180(28 \%)$ & $45(17 \%)$ & $115(25 \%)$ & \\
\hline Agree & $198(31 \%)$ & $21(17 \%)$ & $151(33 \%)$ & \\
\hline Strongly agree & $159(25 \%)$ & $9(7 \%)$ & $136(30 \%)$ & \\
\hline \multicolumn{5}{|c|}{$\begin{array}{l}\text { Educational programs (such as industry-sponsored courses, RUNN course, resident } \\
\text { review courses, AANS/CNS hands-on courses, etc.) provide a supportive and inclu- } \\
\text { sive culture that deals effectively with these behaviors. }\end{array}$} \\
\hline Strongly disagree & $20(3 \%)$ & $7(6 \%)$ & $9(2 \%)$ & \multirow{5}{*}{$<0.001$} \\
\hline Disagree & $40(6 \%)$ & $17(14 \%)$ & $21(5 \%)$ & \\
\hline Neither agree nor disagree & $169(26 \%$ & $47(39 \%)$ & $109(24 \%)$ & \\
\hline Agree & $219(34 \%)$ & $38(31 \%)$ & $152(33 \%)$ & \\
\hline Strongly agree & $195(30 \%)$ & $12(10 \%)$ & $166(36 \%)$ & \\
\hline \multicolumn{5}{|c|}{$\begin{array}{l}\text { Formal/required neurosurgical evaluations and testing procedures ensure a support- } \\
\text { ive and inclusive culture that deals effectively with these behaviors. }\end{array}$} \\
\hline Strongly disagree & $39(6 \%)$ & $18(15 \%)$ & $19(4 \%)$ & \multirow{5}{*}{$<0.001$} \\
\hline Disagree & $86(13 \%)$ & $26(21 \%)$ & $56(12 \%)$ & \\
\hline Neither agree nor disagree & $177(28 \%)$ & $35(29 \%)$ & $123(27 \%)$ & \\
\hline Agree & $195(30 \%)$ & $37(31 \%)$ & $131(29 \%)$ & \\
\hline Strongly agree & $146(23 \%)$ & $5(4 \%)$ & $128(28 \%)$ & \\
\hline \multicolumn{5}{|c|}{$\begin{array}{l}\text { Resident interviews, subinternships, and neurosurgery-related medical school } \\
\text { activities provided a supportive and inclusive culture that deals effectively with these } \\
\text { behaviors. }\end{array}$} \\
\hline Strongly disagree & $43(7 \%)$ & $23(19 \%)$ & $16(4 \%)$ & \multirow{5}{*}{$<0.001$} \\
\hline Disagree & $89(14 \%)$ & $41(34 \%)$ & $40(9 \%)$ & \\
\hline Neither agree nor disagree & $168(26 \%)$ & $24(20 \%)$ & $128(28 \%)$ & \\
\hline Agree & $186(29 \%)$ & $25(21 \%)$ & $140(31 \%)$ & \\
\hline Strongly agree & $157(24 \%)$ & $8(7 \%)$ & $133(29 \%)$ & \\
\hline
\end{tabular}

RUNN = Research Update in Neuroscience for Neurosurgeons.

Boldface type indicates statistical significance. 
TABLE 4. Gender-specific responses to questions regarding personally experiencing discrimination, bullying, and/or sexual harassment

\begin{tabular}{|c|c|c|c|c|}
\hline \multirow[b]{2}{*}{ Survey Question } & \multicolumn{3}{|c|}{ No. of Responses (\%) } & \multirow[b]{2}{*}{$\mathrm{p}$ Value } \\
\hline & All Respondents & Female & Male & \\
\hline \multicolumn{5}{|c|}{$\begin{array}{l}\text { Have you ever been the subject of discrimination, bullying/intimidation } \\
\text { and/or sexual harassment? }\end{array}$} \\
\hline Yes & $334(55 \%)$ & $107(88 \%)$ & $203(44 \%)$ & \multirow{3}{*}{$<0.001$} \\
\hline No & $246(40 \%)$ & $11(9 \%)$ & $227(50 \%)$ & \\
\hline Unsure & $31(5 \%)$ & $3(2 \%)$ & $27(6 \%)$ & \\
\hline \multicolumn{5}{|l|}{ Questions for those responding "yes" } \\
\hline \multicolumn{5}{|c|}{$\begin{array}{l}\text { Where/when have you been the subject of discrimination, bullying/ } \\
\text { intimidation and/or sexual harassment? }\end{array}$} \\
\hline Training & $262(78 \%)$ & $97(91 \%)$ & $152(75 \%)$ & 0.002 \\
\hline National meeting & $55(16 \%)$ & $31(29 \%)$ & $21(10 \%)$ & $<0.001$ \\
\hline Other educational offering & $55(16 \%)$ & $31(29 \%)$ & $22(11 \%)$ & $<0.001$ \\
\hline Postresidency employment & $163(49 \%)$ & $57(53 \%)$ & $99(49 \%)$ & 0.526 \\
\hline \multicolumn{5}{|c|}{ How many times did you experience the behavior? } \\
\hline Once & $14(4 \%)$ & $1(1 \%)$ & $12(6 \%)$ & \multirow{5}{*}{0.030} \\
\hline Fewer than 5 times & $77(24 \%)$ & $20(19 \%)$ & $53(26 \%)$ & \\
\hline Between 5 and 10 times & $62(19 \%)$ & $18(17 \%)$ & $42(21 \%)$ & \\
\hline More than 10 times & $122(37 \%)$ & $51(48 \%)$ & $66(33 \%)$ & \\
\hline Unsure & $52(16 \%)$ & $17(16 \%)$ & $30(15 \%)$ & \\
\hline \multicolumn{5}{|l|}{ How long ago did you experience the behavior? } \\
\hline More than 10 years ago & $138(42 \%)$ & $41(38 \%)$ & $86(42 \%)$ & 0.571 \\
\hline Between 5 and 10 years ago & $97(30 \%)$ & $40(37 \%)$ & $54(27 \%)$ & 0.067 \\
\hline Between 1 and 5 years ago & $113(29 \%)$ & $53(50 \%)$ & $56(28 \%)$ & $<0.001$ \\
\hline Less than 1 year ago & $94(29 \%)$ & $42(39 \%)$ & $48(24 \%)$ & 0.006 \\
\hline Unsure & $4(1 \%)$ & $1(1 \%)$ & $2(1 \%)$ & $>0.999$ \\
\hline \multicolumn{5}{|c|}{ What was the gender of the individual(s) responsible for this behavior? } \\
\hline Female & $17(5 \%)$ & $0(0 \%)$ & $17(8 \%)$ & \multirow{3}{*}{$<0.002$} \\
\hline Male & $236(72 \%)$ & $79(74 \%)$ & $145(71 \%)$ & \\
\hline Both & $74(23 \%)$ & $28(26 \%)$ & $41(20 \%)$ & \\
\hline \multicolumn{5}{|c|}{ What was the position of the individual(s) responsible for this behavior? } \\
\hline Superior & $287(86 \%)$ & $97(91 \%)$ & $177(87 \%)$ & 0.473 \\
\hline Lateral & $143(43 \%)$ & $67(63 \%)$ & $68(33 \%)$ & $<0.001$ \\
\hline Subordinate & $53(16 \%)$ & $29(27 \%)$ & $23(11 \%)$ & $<0.001$ \\
\hline Industry & $34(10 \%)$ & $24(22 \%)$ & $9(4 \%)$ & $<0.001$ \\
\hline Patients/patients' families & $6(2 \%)$ & $4(4 \%)$ & $2(1 \%)$ & 0.215 \\
\hline Administration & $7(2 \%)$ & $3(3 \%)$ & $3(1 \%)$ & 0.710 \\
\hline Nursing staff & $3(1 \%)$ & $1(1 \%)$ & $2(1 \%)$ & $>0.999$ \\
\hline
\end{tabular}

Boldface type indicates statistical significance.

effectively with these behaviors ( $\mathrm{p}=0.014$ and 0.003 , respectively), with similar opinions of neurosurgical evaluations/testing $(\mathrm{p}=0.012)$ and resident interviews, subinternships, and other neurosurgery-related medical school activities $(\mathrm{p}=0.003)$.

Statistically, the younger cohorts had a higher percentage of female neurosurgeons, which does potentially impact the meaning of these findings. After analysis of each gender separately, most of the questions about the environment lost statistical significance except for male neurosurgeons having an age-dependent assessment about the supportive and inclusive culture provided during required neurosurgical evaluations and testing procedures (older cohorts agreed more that the culture was good, $\mathrm{p}=0.012$ ). The younger male cohorts also showed an age-dependent fear of retaliation/retribution that was statistically significant $(p=0.002)$, whereas younger female cohorts had concerns about negative ramifications from the hospital that were statistically significant $(p=0.013)$.

\section{Notable and Poignant Comments}

Reported sexual harassment offenders spanned the 
TABLE 5. Age-specific responses to questions regarding personally experiencing discrimination, bullying, and/or sexual harassment

\begin{tabular}{|c|c|c|c|c|c|}
\hline \multirow[b]{2}{*}{ Survey Question } & \multicolumn{4}{|c|}{ No. of Responses (\%) by Age } & \multirow[b]{2}{*}{$\mathrm{p}$ Value } \\
\hline & $<40$ Yrs & $41-50$ Yrs & $51-60$ Yrs & $>60$ Yrs & \\
\hline \multicolumn{6}{|c|}{$\begin{array}{l}\text { Have you ever been the subject of discrimination, bullying/intimidation } \\
\text { and/or sexual harassment? }\end{array}$} \\
\hline Yes & $97(57 \%)$ & $78(56 \%)$ & $70(54 \%)$ & $67(46 \%)$ & \multirow{3}{*}{0.410} \\
\hline No & $64(38 \%)$ & $53(38 \%)$ & $55(43 \%)$ & $70(48 \%)$ & \\
\hline Unsure & $9(5 \%)$ & $8(6 \%)$ & $4(3 \%)$ & $9(6 \%)$ & \\
\hline \multicolumn{6}{|l|}{ Questions for those responding "yes" } \\
\hline \multicolumn{6}{|c|}{$\begin{array}{l}\text { Where/when have you been the subject of discrimination, bullying/ } \\
\text { intimidation and/or sexual harassment? }\end{array}$} \\
\hline Training & $93(96 \%)$ & $58(74 \%)$ & $55(79 \%)$ & $44(66 \%)$ & $<0.001$ \\
\hline National meeting & $14(14 \%)$ & $12(15 \%)$ & $17(24 \%)$ & $10(15 \%)$ & 0.329 \\
\hline Other educational offering & $20(21 \%)$ & $10(13 \%)$ & $12(17 \%)$ & $12(18 \%)$ & 0.602 \\
\hline Postresidency employment & $19(20 \%)$ & $53(68 \%)$ & $47(67 \%)$ & $39(58 \%)$ & $<0.001$ \\
\hline \multicolumn{6}{|c|}{ How many times did you experience the behavior? } \\
\hline Once & $1(1 \%)$ & $1(1 \%)$ & $3(4 \%)$ & $8(12 \%)$ & \multirow{5}{*}{0.007} \\
\hline Fewer than 5 times & $20(21 \%)$ & $18(23 \%)$ & $18(26 \%)$ & $17(25 \%)$ & \\
\hline Between 5 and 10 times & $22(23 \%)$ & $8(10 \%)$ & $19(27 \%)$ & $11(16 \%)$ & \\
\hline More than 10 times & $41(42 \%)$ & $35(45 \%)$ & $23(33 \%)$ & $19(28 \%)$ & \\
\hline Unsure & $13(13 \%)$ & $16(21 \%)$ & $7(10 \%)$ & $12(18 \%)$ & \\
\hline \multicolumn{6}{|l|}{ How long ago did you experience the behavior? } \\
\hline More than 10 years ago & $7(7 \%)$ & $36(46 \%)$ & $46(66 \%)$ & $40(60 \%)$ & $<0.001$ \\
\hline Between 5 and 10 years ago & $37(38 \%)$ & $27(35 \%)$ & $16(23 \%)$ & $15(22 \%)$ & 0.063 \\
\hline Between 1 and 5 years ago & $46(47 \%)$ & $30(38 \%)$ & $23(33 \%)$ & $11(16 \%)$ & $<0.001$ \\
\hline Less than 1 year ago & $41(42 \%)$ & $26(33 \%)$ & $16(23 \%)$ & $8(12 \%)$ & $<0.001$ \\
\hline Unsure & $0(0 \%)$ & $1(1 \%)$ & $1(1 \%)$ & $1(1 \%)$ & 0.709 \\
\hline \multicolumn{6}{|c|}{ What was the gender of the individual(s) responsible for this behavior? } \\
\hline Female & $6(6 \%)$ & $4(5 \%)$ & $5(7 \%)$ & $2(3 \%)$ & \multirow{3}{*}{0.969} \\
\hline Male & $69(71 \%)$ & $57(73 \%)$ & $50(71 \%)$ & $50(75 \%)$ & \\
\hline Both & $22(23 \%)$ & $17(22 \%)$ & $15(21 \%)$ & $15(22 \%)$ & \\
\hline \multicolumn{6}{|c|}{ What was the position of the individual(s) responsible for this behavior? } \\
\hline Superior & $84(87 \%)$ & $73(94 \%)$ & $62(89 \%)$ & $57(85 \%)$ & 0.377 \\
\hline Lateral & $52(54 \%)$ & $31(40 \%)$ & $30(43 \%)$ & $23(34 \%)$ & 0.079 \\
\hline Subordinate & $20(21 \%)$ & $9(12 \%)$ & $14(20 \%)$ & $10(15 \%)$ & 0.362 \\
\hline Industry & $9(9 \%)$ & $9(12 \%)$ & $8(11 \%)$ & $7(10 \%)$ & 0.959 \\
\hline
\end{tabular}

Boldface type indicates statistical significance.

whole spectrum, from staff to C-suite personnel (i.e., chief executive officer, chief financial officer, chief marketing officer, and similar). Particularly concerning were specific identifications of numerous individuals in positions of leadership. These included hospital administrators, national neurosurgery leaders, deans of medical schools and department chairs, chief residents, neurosurgeons with leadership positions in their institutions, and senior residents. Distressing, too, was the identification of patients and patients' family members as perpetrators of harassment (Supplemental Appendix 2).

In speaking about barriers to reporting concerning behaviors, many troubling comments were added suggesting implied or perceived threats to job, career, optimal training/education, and program probation. Specific comments about witnessed or experienced behaviors were harrowing, especially those in which others saw without assisting or knew without supporting or reporting. All are encouraged to read the honest and poignant comments revealed in Supplemental Appendix 2. These include:

- I was told I was too pretty to be a neurosurgeon and I should just marry one.

- I was physically assaulted by a resident, someone reported it, and my chair was aware but did nothing.

- Unwanted contact and difficulty extracting myself from a prolonged interaction with a powerful, notable and well-connected surgeon... could not create distance between us and felt that more assertive termination would affect my future prospects for my career. 
- A member of industry slipped a "date rape" drug into my drink.

\section{Discussion}

The results from this study demonstrate that, unfortunately, neurosurgeons report significant sexual harassment across all ages and practice settings, affecting both male and female neurosurgeons, with more than half having been personally subjected to this behavior and two-thirds having witnessed it. The seriousness is further suggested by the fact that nearly $40 \%$ of those reporting harassment have experienced this behavior more than 10 times. This confirms many other studies that have identified high rates of sexual harassment in faculty, 1,2,12,17-21 residents, $3,5,6,9,22,23$ and medical students ${ }^{7-10,24,25}$ and within other specialties..$^{5,18,26}$ One meta-analysis indicated a similar rate with a pooled prevalence of $59.5 \%$. Outside of medicine, $81 \%$ believe it is a problem and $54 \%$ of women report some form of harassment. However, this is the first study to measure the incidence across an entire specialty, and it provides urgently needed, accurate, and comprehensive data identifying a critical need within medicine..$^{12}$ The consequences of sexual harassment are serious and significant for neurosurgeons and all neurosurgical institutions. Acknowledging this as a problem is the first critical step in formulating a successful strategy to address it. ${ }^{27}$ Failure to do so only leads to further stigmatization while discouraging open conversation along with full and honest reporting.

The risk of sexual harassment within an institution/ system is associated with three factors: male dominance, a strong hierarchical structure, and a permissive environment. ${ }^{4}$ This study strongly suggests that all three are still present and likely to be responsible factors within neurosurgery. As with other studies of sexual harassment, men were overwhelmingly identified as responsible, $1,2,9,15,19,22$, ${ }^{28,29}$ and the preponderance of harassment confirmed the role of a hierarchical structure by those in superior positions, notably surgical consultants/faculty. ${ }^{3,9,30}$ Neurosurgery has clearly struggled to convince those surveyed that it has created an optimal culture that deals effectively with these behaviors. However, there is good evidence of civility and respect across neurosurgical environments. Failure to report incidents of sexual harassment and fear of reprisal for such reporting were two other strong indicators that neurosurgery can and must do better from a systems perspective to reduce the incidence and consequences of sexual harassment. There is mounting evidence that reduction of inappropriate behaviors must start with leadership providing optimal modeling 4,17,27,31 through appropriate, effective, and longitudinal educational programs. ${ }^{32}$

This study confirms the differential impact of sexual harassment on women across medicine. Numerous studies demonstrate that the perception of sexual harassment risk will influence the selection of specialty ${ }^{7,8,22,24,26}$ and, even within a specialty, the programs that are chosen for training (unpublished work). For more than a decade, organized neurosurgery has been committed to attracting and retaining more women to reach the best and brightest for our specialty. The persistent and pervasive presence of sexual harassment, and the environment that permits it, will continue to undermine these crucial endeavors.

Equally concerning results from this study suggest that younger cohorts-those younger than 40 and between the ages of 41 and 50 years-perceive sexual harassment as a more significant problem than do older cohorts. Also notable was that younger men expressed greater concern about several of the issues than their older colleagues, including the threat of retaliation or retribution. Clearly, there has been a heightened awareness of this topic over the last few years that may contribute to these findings. However, coupling these data with the data that showed a high percentage of reportable events in the previous 5 years strongly suggests that this is not just a historical problem; it continues today, further emphasizing the need for attention.

Within medicine, one of the "hot-button" items today is burnout and the related assessment of physician engagement. ${ }^{33,34}$ There is increasing evidence that sexual harassment and unconscious bias are major contributing factors to female physicians having higher rates of burnout and less institutional engagement. ${ }^{3,35-37}$ Although this study did not attempt to correlate these within neurosurgery, other studies have shown that women have a higher rate of attrition in residency and a lower board pass rate, which might suggest that these factors are responsible. ${ }^{38,39}$ When controlling for sexual harassment, studies suggest that female physicians are more likely to succeed and have job satisfaction equal to their male colleagues. ${ }^{40,41}$ Achieving the same results across neurosurgery will require a change in culture, starting with an improved awareness of unconscious bias in medical school and reaching every level of organized neurosurgery and leadership.

There are many responsible and easy-to-implement policies that can begin this process that, once started, are likely to lead to other changes with further benefit. The establishment of the NSPT was a laudable step, a strong indication that some in organized neurosurgery recognize the need for change. The development of a model policy regarding the reporting of sexual harassment at meetings, educational events, and testing/certification has also been helpful (unpublished work) - with all national neurosurgical organizations adopting this or a similar policy..$^{1,2,42,43}$ However, there is more that must be accomplished, including a zero-tolerance statement across the specialty. There must be a transparent and fair mechanism to report sexual harassment that occurs outside the realm of individual, institutional reporting when applicable. As one example, appropriate planning of social events and limitation of alcohol in settings where there is an increased risk of sexual harassment should be considered. The establishment of "best practices" for social events should be adopted across all neurosurgical organizations and settings. Neurosurgical organizations must select diverse scientific panels, podium speakers, honored guests, etc., because there is clear evidence that diversity is a critical factor in changing the culture and reducing the marginalization of minorities. ${ }^{44,45}$ Through diversity lies the successful future of neurosurgery and all of medicine.

Survey studies always have their challenges. As with other survey studies, our response rate was low, although it was similar to several recent large neurosurgical surveys published (14\% and 15\%). ${ }^{46}$ Thus, the responses may not 
truly reflect the profile or experience of all neurosurgeons (nonresponse bias). Ideally, much more detailed data about the subject and its impact on the individual would have been ideal. However, this had to be balanced to optimize the number and quality of survey responses. Using validated questions when possible, best practices in survey design, and piloting the survey helped to mitigate these concerns. Regardless of these issues, there is no questioning the findings that sexual harassment has been and remains a concern within neurosurgery. Further analysis of the data may reveal patterns of concern that can help focus future study and policy interventions.

\section{Conclusions}

This study demonstrates that neurosurgeons report significant sexual harassment across all ages and practice settings. Sexual harassment impacts both men and women, with more than half personally subjected to this behavior and two-thirds having witnessed it. Responses confirm that factors associated with the risk of sexual harassment-male dominance, a hierarchical environment, and a permissive environment-remain prevalent within the neurosurgical community. Data also indicate that this is not just a historical problem but continues today. A change of culture will be required for neurosurgery to shed this mantle, which must include zero tolerance of this behavior, new policies, awareness of unconscious bias, and commitment to best practices to enhance diversity. Above all, it will require that all neurosurgeons and neurosurgical leaders develop an awareness of sexual harassment in the workplace and implement consistent mechanisms to mitigate against its highly deleterious effects in our specialty.

\section{Acknowledgments}

The One Neurosurgery Summit provided support for the NSPT activity. We acknowledge the dedicated efforts of the AANS/CNS Washington Office and its director for the preparation and distribution of the survey. We further acknowledge the staff of the CNS for their work in survey dissemination. Finally, we thank the entire NSPT for their work related to this survey and all efforts undertaken by this historical task force.

\section{References}

1. Frank E, Brogan D, Schiffman M. Prevalence and correlates of harassment among US women physicians. Arch Intern Med. 1998;158(4):352-358.

2. Vargas EA, Brassel ST, Cortina LM, et al. \#MedToo: a largescale examination of the incidence and impact of sexual harassment of physicians and other faculty at an academic medical center. J Womens Health (Larchmt). 2020;29(1): 13-20.

3. Hu YY, Ellis RJ, Hewitt DB, et al. Discrimination, abuse, harassment, and burnout in surgical residency training. $N$ Engl J Med. 2019;381(18):1741-1752.

4. Johnson PA, Widnall SE, Benya FF, eds. Sexual Harassment of Women: Climate, Culture, and Consequences in Academic Sciences, Engineering, and Medicine. National Academies Press; 2018.

5. Li SF, Grant K, Bhoj T, et al. Resident experience of abuse and harassment in emergency medicine: ten years later. $J$ Emerg Med. 2010;38(2):248-252.

6. Fitzgerald CA, Smith RN, Luo-Owen X, et al. Screening for harassment, abuse, and discrimination among surgery residents: an EAST multicenter trial. Am Surg. 2019;85(5): 456-461.

7. Paiva REA, Vu NV, Verhulst SJ. The effect of clinical experiences in medical school on specialty choice decisions. $J$ Med Educ. 1982;57(9):666-674.

8. Stratton TD, McLaughlin MA, Witte FM, et al. Does students' exposure to gender discrimination and sexual harassment in medical school affect specialty choice and residency program selection? Acad Med. 2005;80(4):400-408.

9. Fnais N, Soobiah C, Chen MH, et al. Harassment and discrimination in medical training: a systematic review and meta-analysis. Acad Med. 2014;89(5):817-827.

10. Richman JA, Flaherty JA, Rospenda KM, Christensen ML. Mental health consequences and correlates of reported medical student abuse. JAMA. 1992;267(5):692-694.

11. Komaromy M, Bindman AB, Haber RJ, Sande MA. Sexual harassment in medical training. N Engl J Med. 1993;328(5): 322-326.

12. Jagsi R, Griffith KA, Jones R, et al. Sexual harassment and discrimination experiences of academic medical faculty. JAMA. 2016;315(19):2120-2121.

13. Murdoch M, McGovern PG. Measuring sexual harassment: development and validation of the Sexual Harassment Inventory. Violence Vict. 1998;13(3):203-216.

14. Fitzgerald LF, Magley VJ, Drasgow F, Waldo CR. Measuring sexual harassment in the military: the Sexual Experiences Questionnaire (SEQ-DoD). Mil Psychol. 1999;11(3):243-263.

15. Bastian LD, Lancaster AR, Reyst HE. Department of Defense 1995 Sexual Harassment Survey. DMDC Report No. 96-014. Defense Manpower Data Center; 1996. Accessed September 24, 2020. https://apps.dtic.mil/dtic/tr/fulltext/u2/a323942.pdf

16. Cantor D, Fisher B, Chibnail S, et al. Report of the Campus Climate Survey on Sexual Harassment and Sexual Misconduct. Westat; 2015. Accessed September 24, 2020. https:// www.aau.edu/sites/default/files/\%40 Files/Climate Survey/ AAU_Campus_Climate_Survey_12_14_15.pdf

17. Dzau VJ, Johnson PA. Ending sexual harassment in academic medicine. N Engl J Med. 2018;379(17):1589-1591.

18. Walsh MN, Gates CC. Zero tolerance for sexual harassment in cardiology: moving from \#MeToo to \#MeNeither. $J$ Am Coll Cardiol. 2018;71(10):1176-1177.

19. Nuthalapaty FS. Sexual harassment in academic medicine: it is time to break the silence. Obstet Gynecol. 2018;131(3): 415-417.

20. Merkin RS, Shah MK. The impact of sexual harassment on job satisfaction, turnover intentions, and absenteeism: findings from Pakistan compared to the United States. Springerplus. 2014;3:215.

21. Morgan AU, Chaiyachati KH, Weissman GE, Liao JM. Eliminating gender-based bias in academic medicine: more than naming the "elephant in the room." J Gen Intern Med. 2018;33(6):966-968.

22. Forel D, Vandepeer M, Duncan J, et al. Leaving surgical training: some of the reasons are in surgery. ANZ J Surg. 2018;88(5):402-407.

23. Karim S, Duchcherer M. Intimidation and harassment in residency: a review of the literature and results of the 2012 Canadian Association of Interns and Residents National Survey. Can Med Educ J. 2014;5(1):e50-e57.

24. Wolf TM, Randall HM, von Almen K, Tynes LL. Perceived mistreatment and attitude change by graduating medical students: a retrospective study. Med Educ. 1991;25(3):182-190.

25. Recupero PR, Heru AM, Price M, Alves J. Sexual harassment in medical education: liability and protection. Acad Med. 2004;79(9):817-824.

26. O'Connor MI. Medical school experiences shape women students' interest in orthopaedic surgery. Clin Orthop Relat Res. 2016;474(9):1967-1972. 
27. Robinson RK, Franklin GM, Fink RL. Sexual harassment at work: issues and answers for health care administrators. Hosp Health Serv Adm. 1993;38(2):167-180.

28. Latcheva R. Sexual harassment in the European Union: a pervasive but still hidden form of gender-based violence. $J$ Interpers Violence. 2017;32(12):1821-1852.

29. US Department of Health and Human Services, Council on Graduate Medical Education. Fifth Report: Women \& Medicine. Published July 1995. Accessed September 24, 2020. https://www.hrsa.gov/sites/default/files/hrsa/advisorycommittees/graduate-medical-edu/reports/archive/1995July.pdf

30. Crebbin W, Campbell G, Hillis DA, Watters DA. Prevalence of bullying, discrimination and sexual harassment in surgery in Australasia. ANZ J Surg. 2015;85(12):905-909.

31. Settles IH, Cortina LM, Malley J, Stewart AJ. The climate for women in academic science: the good, the bad, and the changeable. Psychol Women Q. 2006;30(1):47-58.

32. Jacobs CD, Bergen MR, Korn D. Impact of a program to diminish gender insensitivity and sexual harassment at a medical school. Acad Med. 2000;75(5):464-469.

33. Shanafelt TD, Noseworthy JH. Executive leadership and physician well-being: nine organizational strategies to promote engagement and reduce burnout. Mayo Clin Proc. 2017;92(1): 129-146.

34. West CP, Dyrbye LN, Erwin PJ, Shanafelt TD. Interventions to prevent and reduce physician burnout: a systematic review and meta-analysis. Lancet. 2016;388(10057):2272-2281.

35. Frank E, McMurray JE, Linzer M, Elon L. Career satisfaction of US women physicians: results from the Women Physicians' Health Study. Arch Intern Med. 1999;159(13):1417-1426.

36. Takeuchi M, Nomura K, Horie S, et al. Direct and indirect harassment experiences and burnout among academic faculty in Japan. Tohoku J Exp Med. 2018;245(1):37-44.

37. Leiter MP, Frizzell C, Harvie P, Churchill L. Abusive interactions and burnout: examining occupation, gender, and the mediating role of community. Psychol Health. 2001;16(5): 547-563.

38. Renfrow JJ, Rodriguez A, Liu A, et al. Positive trends in neurosurgery enrollment and attrition: analysis of the 2000-2009 female neurosurgery resident cohort. J Neurosurg. 2016;124(3):834-839.

39. Lynch G, Nieto K, Puthenveettil S, et al. Attrition rates in neurosurgery residency: analysis of 1361 consecutive residents matched from 1990 to 1999. J Neurosurg. 2015;122(2): 240-249.

40. Fitzgerald LF, Drasgow F, Hulin CL, et al. Antecedents and consequences of sexual harassment in organizations: a test of an integrated model. J Appl Psychol. 1997;82(4):578-589.

41. Chan DKS, Lam CB, Chow SY, Cheung SF. Examining the job-related, psychological, and physical outcomes of workplace sexual harassment: a meta-analytic review. Psychol Women Q. 2008;32(4):362-376.
42. American Association of Neurological Surgeons. AANS Policy Regarding Harassment and Disruptive Behavior at Meetings and Courses. Accessed September 24, 2020. https:// www.aans.org/-/media/Files/AANS/About-Us/Governance/ AANS-Policy-Regarding-Harassment-and-DisruptiveBehavior-at-Meetings-and-Courses.ashx

43. American Board of Neurological Surgery. One Neurosurgery Summit Professionalism and Harassment Policy. Published June 26, 2019. Accessed September 24, 2020. https://abns. org/wp-content/uploads/2019/07/professionalism.pdf

44. Witze A. How to counter 'manels' and make scientific meetings more inclusive. Nature. Published online April 2, 2019. doi:10.1038/d41586-019-01022-y

45. Bekker S, Ahmed OH, Bakare U, et al. We need to talk about manels: the problem of implicit gender bias in sport and exercise medicine. Br J Sports Med. 2018;52(20):1287-1289.

46. Kessler RA, Shrivastava RK, Chen SL, et al. Snapshot: socioeconomic competence in US neurosurgery residents. World Neurosurg. 2019;130:e874-e879.

\section{Disclosures}

The authors report no conflict of interest concerning the materials or methods used in this study or the findings specified in this paper.

\section{Author Contributions}

Conception and design: Benzil, Muraszko, Air, Orrico, Rutka. Acquisition of data: Benzil, Orrico, Rutka. Analysis and interpretation of data: all authors. Drafting the article: all authors. Critically revising the article: all authors. Reviewed submitted version of manuscript: all authors. Approved the final version of the manuscript on behalf of all authors: Benzil. Statistical analysis: Benzil, Soni, Air, Rutka.

\section{Supplemental Information Online-Only Content}

Supplemental material is available with the online version of the article.

Supplemental Appendices 1 and 2. https://thejns.org/doi/ suppl/10.3171/2020.6.JNS201649.

\section{Correspondence}

Deborah L. Benzil: Cleveland Clinic, Cleveland, $\mathrm{OH}$. benzild@ccf.org. 